\title{
Modelling of a Chemical Reactor for Simulation of a Methanisation Plant
}

\author{
Bader, A. ${ }^{1} \quad$ Bauersfeld, S. ${ }^{1} \quad$ Brunhuber, C. ${ }^{2} \quad$ Pardemann, R. ${ }^{1} \quad$ Meyer, B. ${ }^{1}$ \\ ${ }^{1}$ Technische Universität Bergakademie Freiberg \\ Department of Energy Process Engineering and Chemical Engineering \\ Fuchsmühlenweg 1, Haus 1, 09599 Freiberg, Germany \\ ${ }^{2}$ Siemens AG, Energy Solutions \\ Freyeslebenstraße 1, 91058 Erlangen, Germany
}

\begin{abstract}
The chemical and physical modelling and transient simulation of a plant with chemical reactors can be useful within dimensioning, optimisation, operation studies and analysing of time critical processes. Therefore, a reactor model for thermodynamic equilibrium conditions has been implemented. The Model is based on the free Modelica Fluid library and contains correlations for heat and mass transfer and pressure drop. The model contains the components: $\mathrm{H}_{2}, \mathrm{CO}, \mathrm{CO}_{2}$, $\mathrm{H}_{2} \mathrm{O}, \mathrm{CH}_{4}, \mathrm{~N}_{2}$

Keywords: chemical reactor; thermodynamic equilibrium; part load; $\mathrm{CO}_{2} ; \mathrm{CO} ; \mathrm{H}_{2} ; \mathrm{CH}_{4} ; \mathrm{H}_{2} \mathrm{O}$
\end{abstract}

\section{Introduction}

It is well known that the oil and natural gas reserves are limeted. The production of fuels is based almost completely on oil and natural gas. Hence there is the wish to extend availibility of a secure energy supply. One solution is the conversion of coal or biomass to synthetic or substitute natural gas (SNG) by gasification and methanation. The reserves of coal will subsist more than 150 years and biomass is a rebewable energy source. The modelling of the SNG synthesis focus only on the methanation step. The simulation of a methanisation plant is in interest for plant manufactures and operators to optimise the construction and the operation. Furthere interest are studies of critical processes for understanding of complex physical and chemical processes in order to increase the reliability and availability of the plant during part load and plant trips.

\section{The SNG synthesis}

The raw gas for the SNG synthesis contains mainly $\mathrm{H}_{2}, \mathrm{CO}, \mathrm{CO}_{2}, \mathrm{H}_{2} \mathrm{O}, \mathrm{CH}_{4}, \mathrm{~N}_{2}$. This composition of the raw gas depends on the gasification technology. The SNG synthesis is a heterogeneously catalysed process. During the methanation, the following chemical reactions execute. The hydrogenation of carbon oxides to methane are the so called $\mathrm{CO}$ methanation reaction in equation 1 and the $\mathrm{CO}_{2}$ methanation reaction in equation 2.

$$
\begin{gathered}
\mathrm{CO}+3 \mathrm{H}_{2} \rightleftharpoons \mathrm{CH}_{4}+\mathrm{H}_{2} \mathrm{O} \\
\mathrm{CO}_{2}+4 \mathrm{H}_{2} \rightleftharpoons \mathrm{CH}_{4}+2 \mathrm{H}_{2} \mathrm{O}
\end{gathered}
$$

Two further independent reactions are important: the CO-Shift reaction in equation 3 and the Boudouard reaction in equation 4.

$$
\begin{gathered}
\mathrm{CO}+\mathrm{H}_{2} \mathrm{O} \rightleftharpoons \mathrm{H}_{2}+\mathrm{CO}_{2} \\
2 \mathrm{CO} \rightleftharpoons \mathrm{C}+\mathrm{CO}_{2}
\end{gathered}
$$

All the reactions of the methanation are exothermic, see Table 1 . The methanation is favoured at low temperatures. Futhermore the methanation is benefited at high pressure, as the reaction 1 and 2 execute with volume decreasing.

The major criteria of catalysed methanation reactors is to achieve efficient removal of heat. The first reason is to minimise catalyst deactivation due to thermal stress. The second reason is to avoid a limitation in the methane yield due to approaching the chemical equlibrium. The Topsøe recycle energy-efficient methanation process (TREMP) from Haldor Topsøe is 
Table 1: Reaction heat at standard conditions reaction reaction heat, $\Delta_{R} H^{0}$

\begin{tabular}{cc} 
& $\mathrm{kJ} / \mathrm{mol}$ \\
\hline 1 & -206 \\
2 & -165 \\
3 & -41 \\
4 & -172 \\
\hline
\end{tabular}
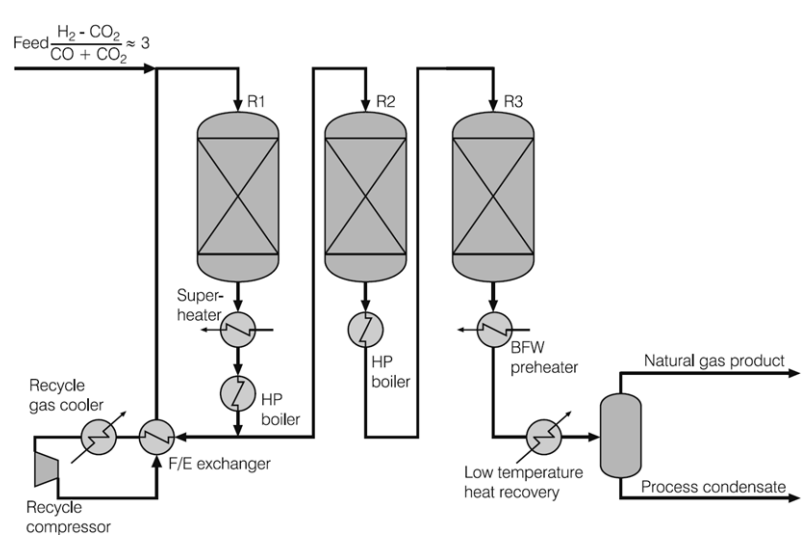

Figure 1: Flowsheet of the Topsøe recycle energyefficient methanation process [1]

a suitable reactor concept for the production of SNG [1], which is used for the modelling.

The TREMP consists of 3 adiabat fixed bed reactors with gas recycle cooling and interstage cooling. Efficient recovery of the reaction heat is essential for the industrial methanation technology. That's why a counter current water cycle stream is used for the interstage cooling. The water cycle is simultaneously used for high pressure steam generation. The gas recycle at the first reactor reduces the yield and the temperature in the reactor.

\section{Developed models}

The aim of the modelling is to implement a library with physical based models of components of the TREMP methanation plant. The library enables investigations with models of a reactor, a heat exchanger, a simple pump, a flash, a gas and water splitter. The implemented library is based on the free Modelica Fluid library, which offers a base with respect to the implementation of the three balance equations and the interaction through the fluid ports.

\subsection{Reactor}

It is necessary to calculate the thermodynamic equlibrium for the methanation reactor yield, as it will be
Table 2: Parameters $A$ and $B$ of equation 10

\begin{tabular}{crr}
\hline reaction & $\mathrm{A}$ & $\mathrm{B}$ \\
\hline 1 & -29.3014 & 26248.4 \\
3 & -4.3537 & 4593.2 \\
\hline
\end{tabular}

achieved both in the full load and the part load of the methanation plant, Harms in [2]. The thermodynamic equilibrium constant $K_{a}$ is used in relation with the law of mass action to determine the molar fractions of the components and the yield of the reactions at the thermodynamic equilibrium. $K_{P}$ is the equilibrium constant of the partial pressures, $p_{i}$, of the species, which is connected to the $K_{a}$ with the fugacity coefficients, $K_{\alpha}$, in equation 5 .

$$
K_{P}=\frac{K_{a}}{K_{\alpha}}
$$

The law of mass action for the $K_{P}$ is described in equation 6 for a chemical reaction like in equation 7 .

$$
\begin{gathered}
K_{P}=\frac{p_{C}^{\vartheta_{C}} \cdot p_{D}^{\vartheta_{D}}}{p_{A}^{\vartheta_{A}} \cdot p_{B}^{\vartheta_{B}}} \\
\vartheta_{A} A+\vartheta_{B} B \rightleftharpoons \vartheta_{C} C+\vartheta_{D} D
\end{gathered}
$$

The equilibrium constant of the molar fractions $\left(K_{X}\right)$ is necessary to calculate the chemical equilibrium. $K_{X}$ can be compute with $K_{P}$, the total pressure, $p$, and the sum of stoichiometry coefficients of the chemical reaction, how it is shown in equation 8 . The molar fraction of the species, $X_{i}$, can be determined with equation 9.

$$
\begin{gathered}
K_{X}=K_{P} \cdot p^{-\sum \vartheta_{i}} \\
K_{X}=\frac{X_{C}^{\vartheta_{C}} \cdot X_{D}^{\vartheta_{D}}}{X_{A}^{\vartheta_{A}} \cdot X_{B}^{\vartheta_{B}}}
\end{gathered}
$$

It has to be noted that the thermodynamic equilibrium constant is temperature dependent. The temperature can be approximated with equation 10 .

$$
\ln \left(K_{a}\right)=A+\frac{B}{T}
$$

The parameters $A$ and $B$ of equation 10 are given in Table 2.

Two simplification were assumpted for the calculation of the thermodynamic equlibrium. The first is the assumption of ideal gas law for the species. Therewith the fugacity coefficients can be neglected in equation $5, K_{\alpha}=1$. 
The second simplification is the neglect of the Boudouard reaction, equation 4, which occurs if the stoichiometry ratio of equation 11 is lower than 3 . In that case, carbon is produced as a product of reaction 4. Carbon leads to catalyst deactivation by forming of carbon deposition on the catalyst surface.This is the technical aspect to elimate reaction 4 .

$$
\frac{\mathrm{H}_{2}-\mathrm{CO}_{2}}{\mathrm{CO}+\mathrm{CO}_{2}} \geq 3
$$

If the stoichiometriy ratio from the reactants of equation 11 is at least 3 or more, $\mathrm{CO}$ reacts with $\mathrm{H}_{2}$ completly to $\mathrm{CH}_{4}$ and $\mathrm{H}_{2} \mathrm{O}$ according to equation 1 . The stoichiometry ratio of equation 11 can be adjusted by converting $\mathrm{CO}$ with $\mathrm{H}_{2} \mathrm{O}$ to $\mathrm{CO}_{2}$ and $\mathrm{H}_{2}$ as long as the $\mathrm{H}_{2} \mathrm{O}$ ist high enough, see Anderlohr in [3].

Finally the system of methanation reactions can be reduced to reaction 1 and 3 , as the stoichiometry ratio of equation 11 for all the gas streams in the TREMP are higher than three. Therewith the molar fraction of the species can be determined with the equations from 12 to 17 , in which 0 stands for the start state and 1 for the equilibrium state. The yield $U_{1}$ and $U_{2}$ is the yield of the reactions 1 and 3 , whose sum is the total yield of $\mathrm{CO}$, see equation 18 .

$$
\begin{gathered}
X_{H_{2}, 1}=\frac{C_{H_{2}, 0}-3 C_{C O, 0} \cdot U_{1}+C_{C O, 0} \cdot U_{2}}{1-2 \cdot C_{C O, 0} \cdot U_{1}} \\
X_{C H_{4}, 1}=\frac{C_{C H_{4}, 0}+C_{C O, 0} \cdot U_{1}}{1-2 \cdot C_{C O, 0} \cdot U_{1}} \\
X_{H_{2} O, 1}=\frac{C_{H_{2} O, 0}+C_{C O, 0} \cdot U_{1}-C_{C O, 0} \cdot U_{2}}{1-2 \cdot C_{C O, 0} \cdot U_{1}} \\
X_{C O, 1}=\frac{C_{C O, 0}-C_{C O, 0} \cdot U_{1}-C_{C O, 0} \cdot U_{2}}{1-2 \cdot C_{C O, 0} \cdot U_{1}} \\
X_{C O_{2}, 1}=\frac{C_{C O_{2}, 0}+C_{C O, 0} \cdot U_{2}}{1-2 \cdot C_{C O, 0} \cdot U_{1}} \\
X_{N_{2}, 1}=\frac{C_{N_{2}, 0}}{1-2 \cdot C_{C O, 0} \cdot U_{1}} \\
U_{1}+U_{2}=\frac{C_{C O, 0}-C_{C O, 1}}{C_{C O, 0}}
\end{gathered}
$$

In order to determine the chemical equilibrium at known temperature and pressure, a non-linear equation system of the above mentioned equations need to be solved. The results of an example calculation are given in Figure 2.

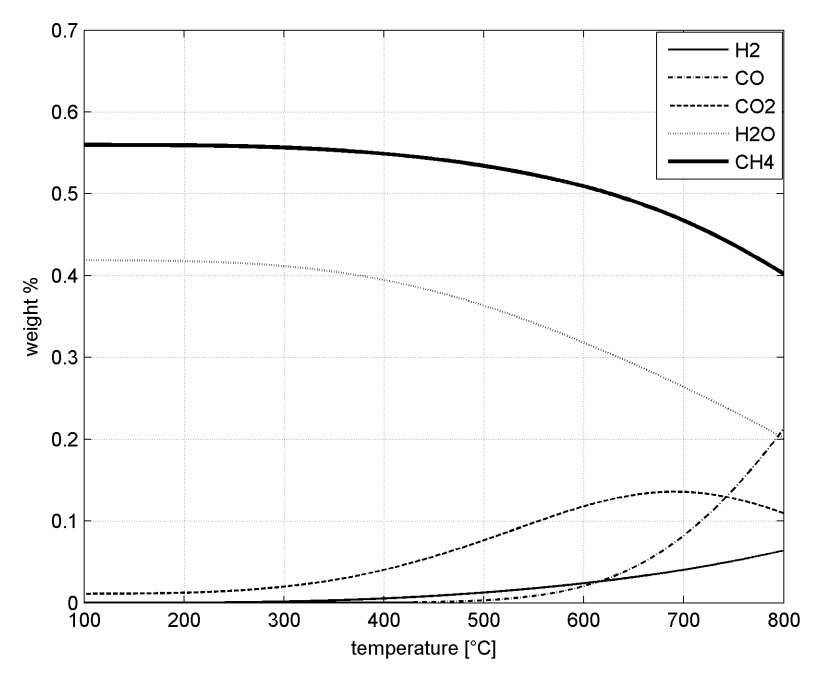

Figure 2: Thermodynamic equilibrium for the feed gas in the range of $100-800{ }^{\circ} \mathrm{C}$ at $30 \mathrm{bar}$, start composition in w.\%: 4,97 $\mathrm{H}_{2}, 13,80 \mathrm{CO}, 11,97 \mathrm{CO}_{2}, 24,11 \mathrm{H}_{2} \mathrm{O}$, $44,12 \mathrm{CH}_{4}, 1,03 \mathrm{~N}_{2}$;

Table 3: Parameters $A, B$ and $C$ of equation 20

\begin{tabular}{crrr}
\hline reaction & A & B & C \\
\hline 1 & 0.0266 & -47.7331 & -205094.5788 \\
3 & 0.0026 & -7.4437 & -41557.3842 \\
\hline
\end{tabular}

The energy balance need to be completed by the produced reation heat which influence the equilibrium temperature. The amount of the produced reaction heat is the higher the yield of the reactions is. A high reaction heat leads to high temperatures. But the higher the temperature, the lower is the yield. The reaction heat, $\dot{Q}_{R k t}$, can be determined by equation 19 , in which $\Delta h$ is the specific enthalpy of the reaction and $M_{\text {gas }}$ the mean molar mass of the gas. The temperature dependency of the specific reaction enthalpy is approximated with equation 20 . The parameters of equation 20 for reaction 1 and 3 are given in Table 3 .

$$
\begin{gathered}
\dot{Q}_{R k t}=\left(\Delta h_{R-1} \cdot U_{1}+\Delta h_{R-3} \cdot U_{2}\right) \\
\cdot \dot{m} \cdot\left(\frac{X_{C O, 1}}{M_{\text {gas }, 1}}-\frac{X_{C O, 0}}{M_{\text {gas }, 0}}\right) \\
\Delta h=A \cdot T^{2}+B \cdot T+C
\end{gathered}
$$

The configuration of the reactor model is shown in Figure 3. The model components are sNG_reaction model, volume, heat capacity, temperature sensor and linear valve with a constant block. The calculation of the thermodynamic equilibrium occurs in the sNG_reaction model. The volume represents the volume of the reactor. The heat capacity model is the heat 
capacity of the catalyst bed and the reactor wall. The valve model is used to simulate the pressure drop of gas flow through the catalyst bed.

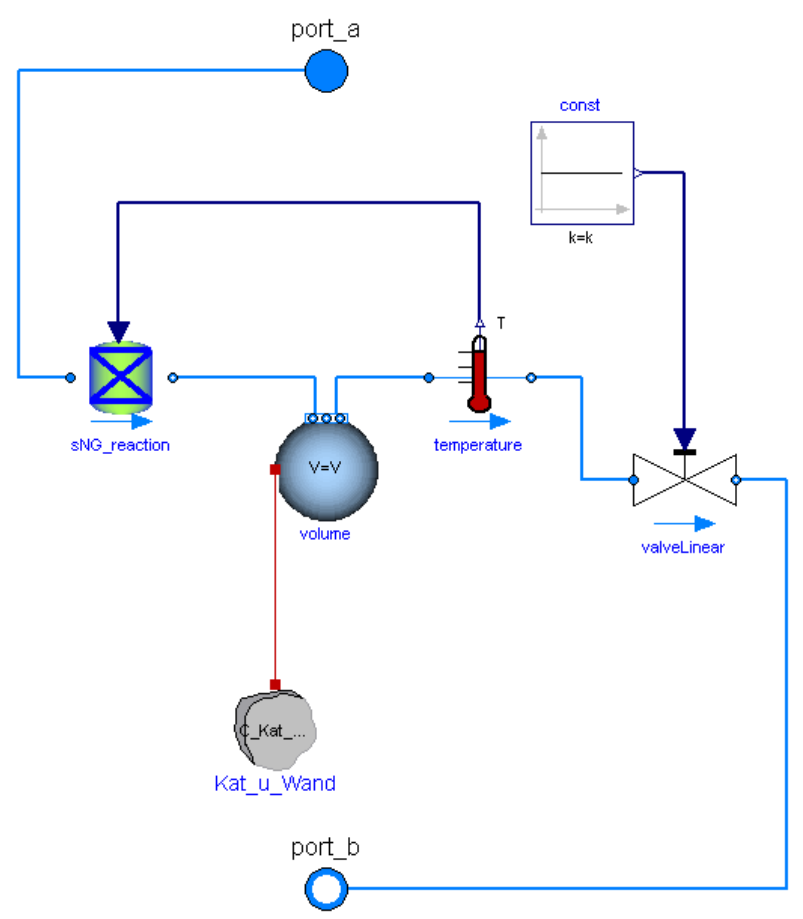

Figure 3: Configuration of the reactor model

The reactor model has three main parameters: volume, pressure drop and heat capacity. The parameters have different impact of the reactor performance. The greater the reactor volume, the later will be the steady state achieved. The pressure drop changes the pressure and therewith the reactor yield. The pressure drop is predefined by the user.The impact of the heat capacity is more difficult. The reactor model need be splitted in series identical reactor zones, which are duplicates of the reactor model configuration in Figure 3, at high heat capacities. The higher the heat capacity, the more zones are needed to get the steady state for temperature and methane at the same time, which is physically nescessary, because the temperature influence the chemical equilibrium. The temperature would be change slower than the chemical equilibrium, if the number of zones is to low. An example of the transient temperature behaviour for an 5 zone reactor model at heat capacities in the range of 0 to $10 \mathrm{MJ} / \mathrm{K}$ is given in Figure 4 . The consequently methane concentration is illustrated in Figure 5.

The reactor ignition or extinction can not be simulated, because no attention is paid to kinetic effects of the chemical reactions.

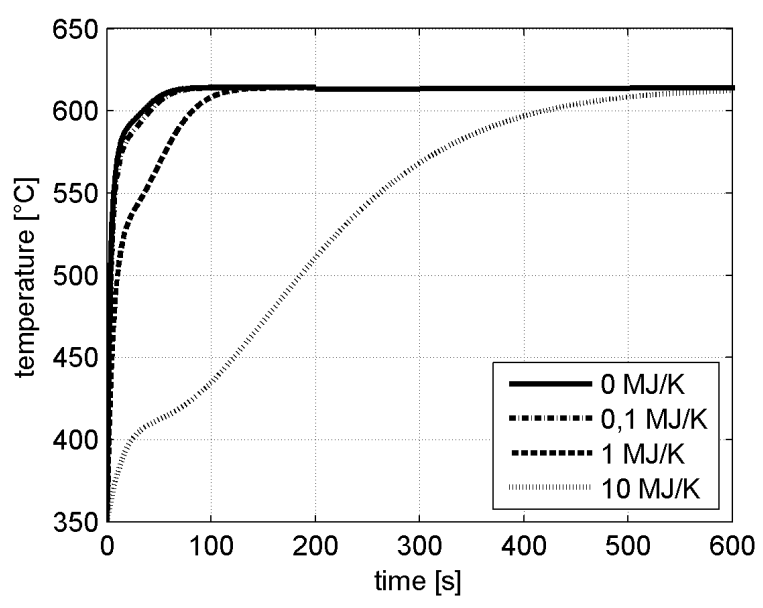

Figure 4: Temperature for a reactor model with 5 zones at heat capacities in the range of 0 to $10 \mathrm{MJ} / \mathrm{K}$

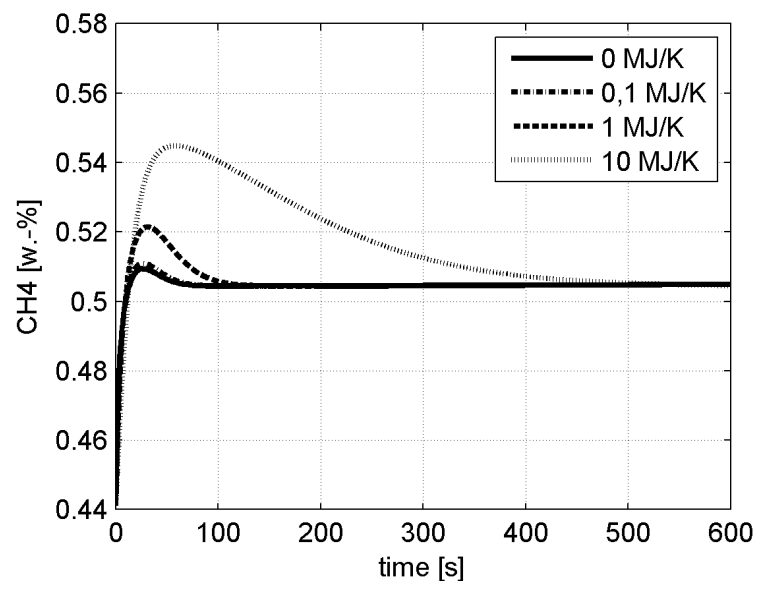

Figure 5: Methane concentration for a reactor model with 5 zones at heat capacities in the range of 0 to 10 $\mathrm{MJ} / \mathrm{K}$

\subsection{Heat exchanger}

The second important model for the modelling of the methanisation plant is the heat exchanger, which is assumed with a simple design. The heat exchanger design comprises of an outside tube, filled with hot SNG gas, which has an inside tube filled with water, how it is shown in Figure 6. The configuration of a heat exchanger zone is given in Figure 7. The zone consists of two volume models. One volume model contains SNG gas and the other water/steam. The volume model are connected by a thermal conduction model. The heat exchanger comprises of such series zones. The water and the gas are in counter current flow as the fluid ports are setted up in this way. Multiple zones are necessary therewith the outflow of the cold side can be hotter than the outflow of hot side, in certain cases. Further- 
more, a temperature profil can be generated accross the heat exchanger because of the multiple zones.

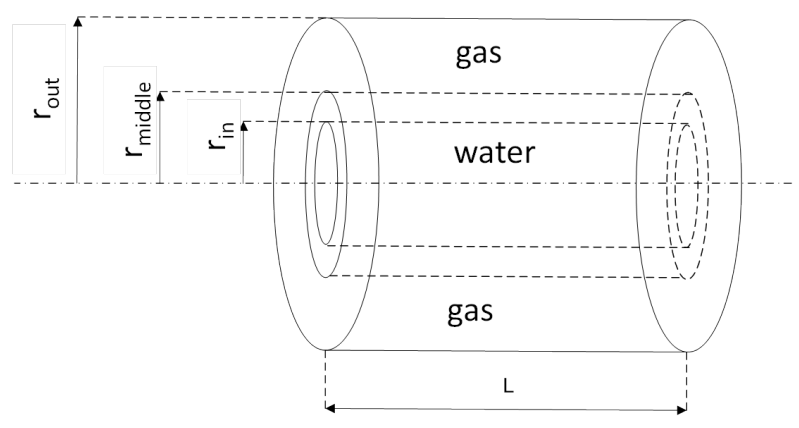

Figure 6: Heat exchanger design

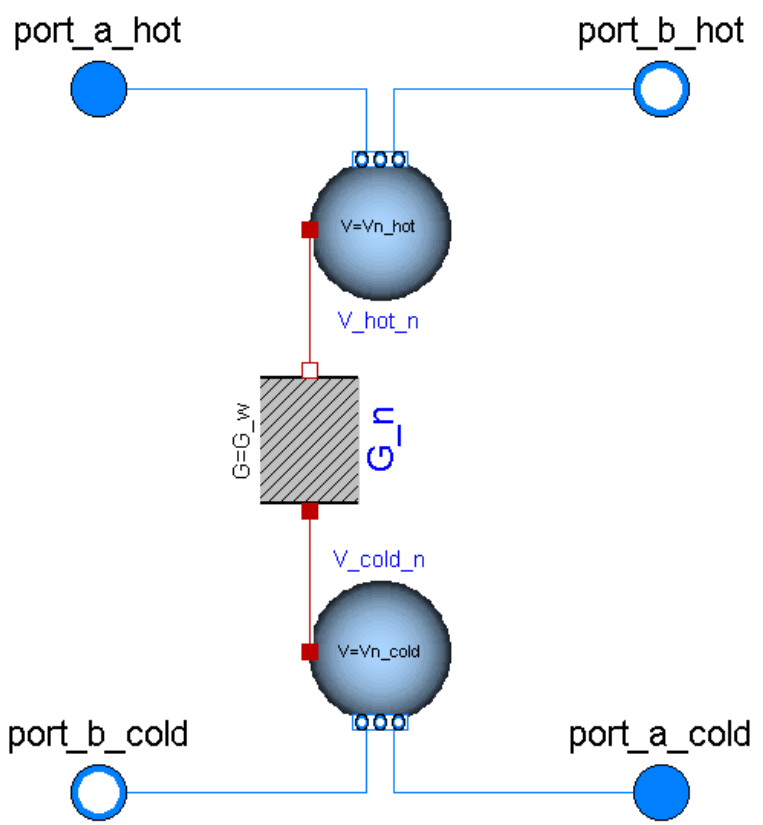

Figure 7: Configuration of a heat exchanger zone

The steady state results of an example simulation are given in Figure 8. The water temperature is constant in the beginning part of the heat exchanger, as the boiling point is achieved at $318{ }^{\circ} \mathrm{C}$ at 110 bar. The gas temperature is cooled down continuously.

\section{Validation}

The steady state results from the simulation will be validated in the following section as well from the single reactor model as the complexe model of the methanation plant. The results are compared to two references. The first one are the experimental results of the TREMP which are published by Harms in [2]. The second reference are steady state simulation results with the software ChemCAD which assumes the

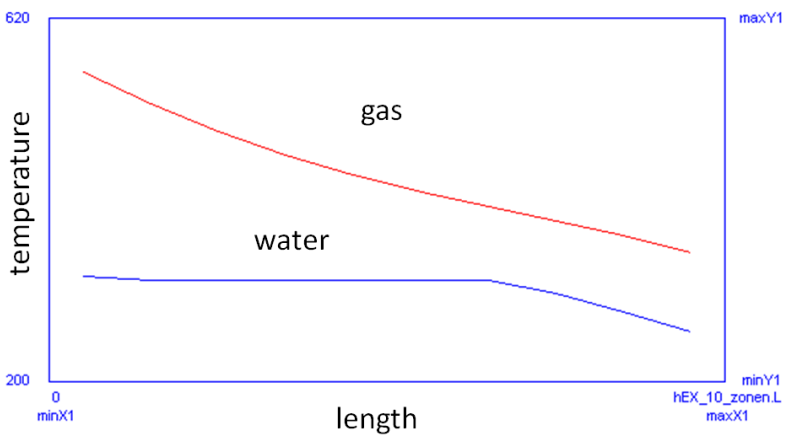

Figure 8: Temperatures of the heat exchanger model at steady state

chemical equlibrium. The results of the reactor model are compared with the data of these two references in Table 4 and of the TREMP model in Table 5. The misstake of the species is always lower than $4 \%$ except of hydrogen at low concentration, where the mistake is under certain conditions up to $10 \%$.

Table 4: Comparison of the outlet gas composition of the first reactor of the TREMP with the reactor model in Modelica and in ChemCAD. Inlet gas: composition in weight \%: 4,97 $\mathrm{H}_{2}, 13,80 \mathrm{CO}, 11,97 \mathrm{CO}_{2}, 24,11$ $\mathrm{H}_{2} \mathrm{O}, 44,12 \mathrm{CH}_{4}, 1,03 \mathrm{~N}_{2}$; temperature $300{ }^{\circ} \mathrm{C}$; pressure $30 \mathrm{bar}$

\begin{tabular}{ccrrr} 
& Unit & $\begin{array}{r}\text { Outlet } \\
\text { TREMP }\end{array}$ & $\begin{array}{r}\text { Outlet } \\
\text { Modelica }\end{array}$ & $\begin{array}{r}\text { Outlet } \\
\text { ChemCAD }\end{array}$ \\
\hline Temp. & ${ }^{\circ} \mathrm{C}$ & 600 & 600 & 599 \\
\hline $\mathrm{H}_{2}$ & w.\% & 2,47 & 2,40 & 2,41 \\
$\mathrm{CO}$ & w.\% & 2,01 & 2,04 & 1,97 \\
$\mathrm{CO}_{2}$ & w.\% & 12,13 & 11,79 & 11,92 \\
$\mathrm{H}_{2} \mathrm{O}$ & w.\% & 31,48 & 31,82 & 31,76 \\
$\mathrm{CH}_{4}$ & w.\% & 50,82 & 50,92 & 50,91 \\
$\mathrm{~N}_{2}$ & w.\% & 1,10 & 1,03 & 1,03 \\
\hline
\end{tabular}

\section{Transient behaviour}

The reactor and the heat exchager model, see section 3, are used to build up the model of the methanstion plant like it is shown in Figure 1. The model of the methanation plant is utilised for transient simulation studies. In the following, results of a part load simulation are presented. The simulation of the load change is faster than realtime. In order to realise the part load, the feed mass stream was reduced to $50 \%$ after the TREMP model is steady state which is after $300 \mathrm{~s}$ simulation time, see Figure 9. The steady state in part load is achieved after the simulation time $1000 \mathrm{~s}$. 
Table 5: Comparison of the outlet gas composition of the first reactor of the TREMP with the TREMP model in Modelica and in ChemCAD. Inlet gas: composition in weight \%: $13,08 \mathrm{H}_{2}, 51,76 \mathrm{CO}, 11,49 \mathrm{CO}_{2}, 0,00$ $\mathrm{H}_{2} \mathrm{O}, 22,54 \mathrm{CH}_{4}, 1,13 \mathrm{~N}_{2}$; temperature $150{ }^{\circ} \mathrm{C}$; pressure 30 bar. Recycle rate $=3,3$

\begin{tabular}{ccrrr}
\hline & Unit & $\begin{array}{r}\text { Outlet } \\
\text { TREMP }\end{array}$ & $\begin{array}{r}\text { Outlet } \\
\text { Modelica }\end{array}$ & $\begin{array}{r}\text { Outlet } \\
\text { ChemCAD }\end{array}$ \\
\hline Temp. & ${ }^{\circ} \mathrm{C}$ & 600 & 596 & 594 \\
\hline $\mathrm{H}_{2}$ & w.\% & 2,47 & 2,34 & 2,34 \\
$\mathrm{CO}$ & w.\% & 2,01 & 1,91 & 1,83 \\
$\mathrm{CO}_{2}$ & w.\% & 12,13 & 11,64 & 11,73 \\
$\mathrm{H}_{2} \mathrm{O}$ & w.\% & 31,47 & 31,94 & 31,91 \\
$\mathrm{CH}_{4}$ & w.\% & 50,82 & 51,04 & 51,06 \\
$\mathrm{~N}_{2}$ & w.\% & 1,10 & 1,13 & 1,13 \\
\hline
\end{tabular}

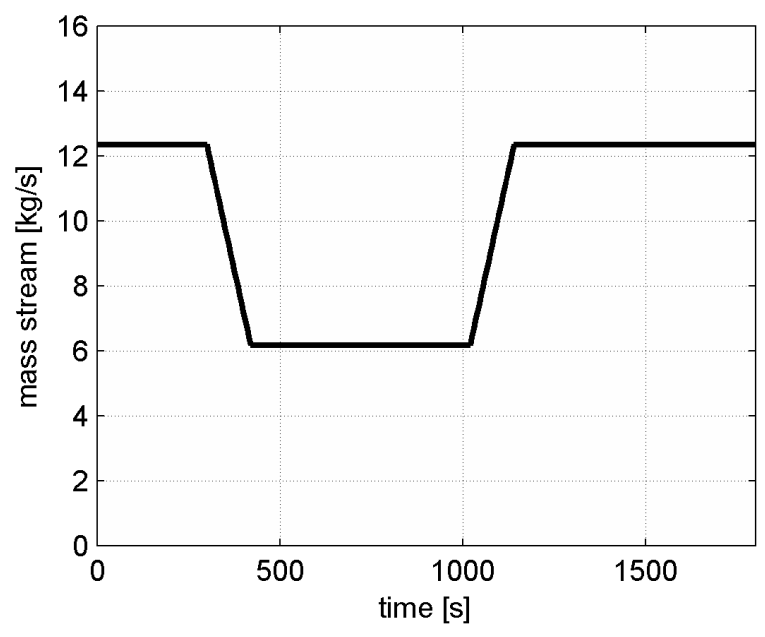

Figure 9: Mass stream of the feed in the Modelica TREMP model

The result are lower gas temperatures in the reactors which leads to higher methane concentrations in the gas, how it is shown in Figure 10 and 11. The feed mass stream rise back up to $100 \%$ after $1000 \mathrm{~s}$ simulation time to full load. The steady state is got after simulation time $2000 \mathrm{~s}$. The temperature and the methane concentration achieve the same level as before the part load.

Finally the gas product quality at part load is almost equal to the full load. Furthermore, it is still possible to produce steam, but the pressure of the steam need to be adjusted.

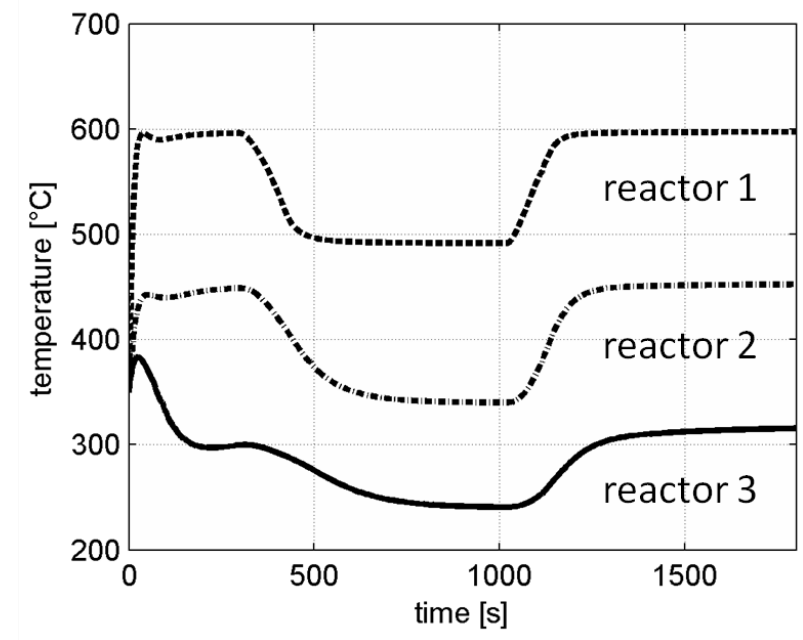

Figure 10: Temperatures in the reactors in the Modelica TREMP model

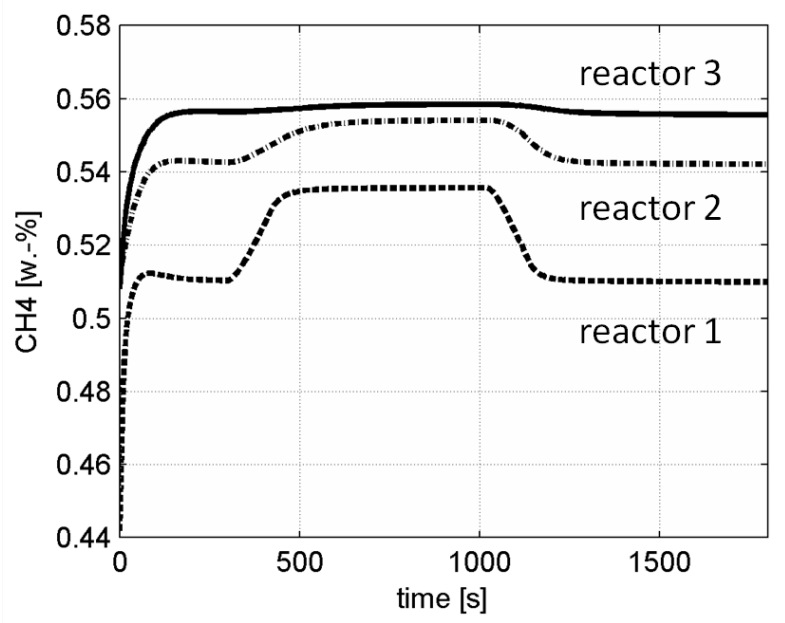

Figure 11: Methane concentration in the reactors in the Modelica TREMP model

\section{Conclusion}

A succesfull generation of a dynamic methanation plant model could be realised. Therefore the development of a simplified reactor and heat exchanger model was necessary. The results of the reactor plant and the plant model of the TREMP could be validated successful of steady state performance with ChemCAD simulations and experimental data from Harms [2]. The dynamic behaviour could be only validated by a plausibility check.

The TREMP plant model is finally useful for the development and check of control concepts, and furthermore for the analysis of trip scenarios and load changes. 


\section{Outlook}

It has to be mentioned that the solution of the nonlinear equation system takes a long calculation time of the CPU, because the slow mixed implicied/expliced euler method is used for simulation. All the other integrated numerical solution algorithms in Dymola lead to instability. Hence, a faster and more stable solution algorithm for the calculation of the thermodynamic equlibrium is neseccary. One proposal is to work with look up tables which are precalculated for certain reactor yields. The disadvantage of this solution is a reduced flexibility of the model. Another proposal is the use of the so called method: minimisation of the gibbs enthalpie, for the calculation of the thermodynamic equibrium, which is published by White et al. in [4]. At this method solves mainly derivatives, the equation system may be solved much faster and more numeric robust.

Moreover, a kinetic model is necessary to estimate the limits for the parameter therewith the assumption of the thermodynamic equlibrium can be justified.

\section{References}

[1] Haldor Topsoe: From solid fuels to substitute natural gas (SNG) using TREMP, http://www.topsoe.com

[2] Harms, H.; Höhlein, B.; Skov, A.; Methanisierung kohlenmonoxidreicher Gase beim Energietransport. In: Chemie.-Ing. Technik, (6) page 504-515, 1980.

[3] Anderlohr, A.; Untersuchung zu gleichzeitigen Methanisierung und Konvertierung von CO-reicher Gase in einer katalytischen Wirbelschicht. Karlsruhe, Germany: PhD thesis, Fakultät für Chemieingenieurwesen, Tech. Hochschule Karlsruhe, 1979.

[4] White, W.; Johnson, S., Danzig, G.: Chemical Equilibrium in Complex Mixtures. In: The Journal of Chemical Physics 28(5), S. 751-755 (1958) 